\title{
Endometrial blood flow in rats during early pregnancy
}

\author{
N. Einer-Jensen \\ Department of Physiology, Odense University, DK 5000 Odense, Denmark
}

In the rat, total uterine blood flow is maximal during peak secretion of oestrogen (Spaziani \& Suddick, 1967; Greiss \& Anderson, 1973). This is probably due to a high rate of flow through the myometrium, since endometrial blood flow has been shown to be twice as high during dioestrus as during oestrus (Einer-Jensen, 1976). If the high endometrial blood flow in dioestrus is associated with progestagen secretion, a high endometrial blood flow in early pregnancy would be anticipated. This supposition was examined in the present study.

Adult female Charles River rats were used after they had previously been proved fertile. Prooestrous animals were selected after examination of the vaginal lavage and caged overnight with males. Those with spermatozoa in the vagina were considered pregnant (Day 1) and used for the blood flow measurements on Days 1-6. After induction of anaesthesia with an i.p. injection of $30 \mathrm{mg}$ pentobarbitone sodium (Nembutal) $/ \mathrm{kg}$, a tracheostomy was performed and polyethylene catheters (Clay Adams PE 20), filled with heparin-saline, were inserted into a jugular vein and a common carotid artery. The tip of the carotid catheter was placed in or close to the aorta, and a small quantity $(0.19 \mathrm{ml} / \mathrm{min})$ of $0.85 \%(\mathrm{w} / \mathrm{v}) \mathrm{NaCl}$ solution was infused through the jugular catheter throughout the experimental period to stabilize the general circulation. The abdomen was opened and a miniature Geiger-Müller tube (thin-walled stainless-steel, diameter $1.5 \mathrm{~mm}$, length $8 \mathrm{~mm}$ ) mounted in the tip of a stainless-steel rod (type 5107: EON Corporation, Brooklyn, New York) was inserted in the lumen of each uterine horn through incisions close to the cervix.

To measure endometrial blood flow, ${ }^{85} \mathrm{krypton}$ dissolved in $0.2 \mathrm{ml} 0.85 \% \mathrm{NaCl}$ was injected through the arterial catheter from a $1 \mathrm{ml}$ syringe by means of an infusion pump activated for $3 \mathrm{sec}$. The original $2 \mathrm{ml}$ of saline solution (sp. act. approx. $20 \mathrm{Ci} / \mathrm{g}$ : New England Nuclear) containing $10 \mathrm{mCi}^{85} \mathrm{Kr}$ was diluted to $5 \mathrm{ml}$ giving a dose of $0.4 \mathrm{mCi} /$ injection.

Four krypton injections were given to each animal. The impulses from the probes were counted and printed in 10-sec intervals by two modified DOT counters (EON Corporation). The radioactivity registered by the probes was plotted on semilogarithmic graph sheets and the time $(t / 2)$ taken for it to decrease to half the initial level was calculated. Blood flow was calculated from the formula:

$$
\frac{\ln 2 \times K}{\mathrm{t} / 2} \mathrm{ml} \cdot \mathrm{g}^{-1} \cdot \mathrm{min}^{-1}
$$

assuming a partition coefficient $K$ of 0.85 (Setchell, Waites \& Thorburn, 1966). This value for $K$ was obtained in ram testis but that for endometrium should not be greatly different, as the fat content of the two organs is similar.

Table 1. Endometrial blood flow (mean \pm S.E.M., $\mathrm{ml} \cdot \mathrm{g}^{-1} \cdot \mathrm{min}^{-1}$ ), measured by the krypton- 85 clearance method in rats during early pregnancy

\begin{tabular}{lcccccc}
\hline & \multicolumn{6}{c}{ Day of pregnancy } \\
\cline { 2 - 7 } & 1 & 2 & 3 & 4 & 5 & 6 \\
\hline $\begin{array}{l}\text { No. of } \\
\text { measurements }\end{array}$ & 6 & 8 & 19 & 23 & 40 & 36 \\
1st compartment & $1.92 \pm 0.69$ & $2.41 \pm 0.15$ & $2.38 \pm 0.23$ & $3.47 \pm 0.25$ & $2.91 \pm 0.06$ & $3.59 \pm 0.08$ \\
2nd compartment & $0.50 \pm 0.01$ & $0.59 \pm 0.00$ & $0.63 \pm 0.03$ & $0.69 \pm 0.03$ & $0.52 \pm 0.01$ & $0.96 \pm 0.02$ \\
\hline
\end{tabular}




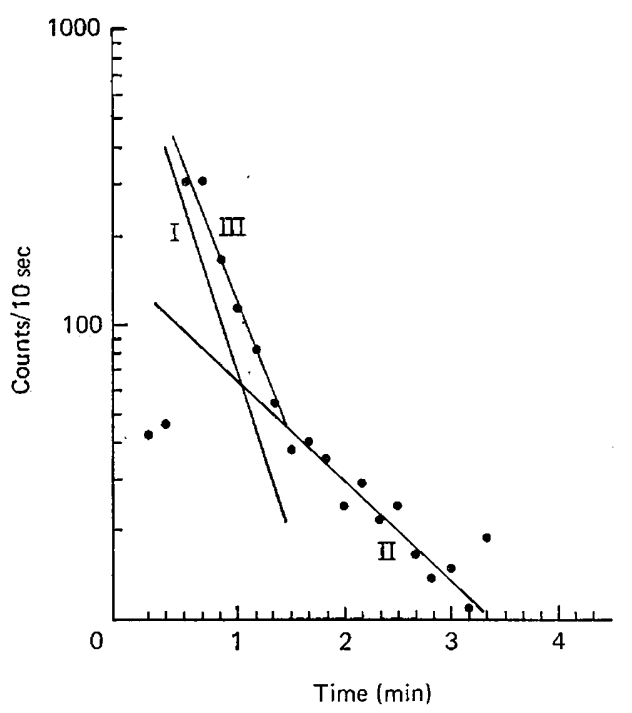

Text-fig. 1. Clearance of krypton-85 from the endometrium after injection of ${ }^{85} \mathrm{Kr}$ saline into the aorta. Line $I$ is taken to represent the first compartment, and Line II the second.

Measurements (132) were obtained from 25 animals (Table 1). From the semilogarithmic plots the clearance curves could be fitted by two straight lines (Text-fig. 1). The less steep of these (Line II) was taken to represent a second compartment. A straight line (Line I) representing a first compartment was constructed by subtracting the extrapolated values of Line II from those used to construct the Line III.

Lines I and II may be taken to represent flow through two different capillary beds within the endometrium because ${ }^{85}$ krypton is almost exclusively a beta-emitting isotope. The radiation is very soft; less than $1 \mathrm{~mm}$ tissue will absorb close to $100 \%$ of the energy. It is therefore likely that the gas clearance measured will involve only a thin cylinder of the endometrial tissue touching the probe situated in the lumen. Although this has yet to be confirmed by experimental evidence, it seems improbable that compartments I and II originate from a simultaneous measurement of endometrial and myometrial blood flow.

The uterine lumen was often distended by a highly viscous fluid on the day of mating (Day 1), which precluded close connection between the probe and the endometrium. Both initial increase in radioactivity and the clearance rate after the injection of ${ }^{85}$ krypton on Day 1 of pregnancy were often slow and monoexponential. These curves were not included in the present material as they probably represent the diffusion of gas through a non-vascularized area rather than blood flow measurements. These findings thus support the hypothesis that the fast clearance found in the other animals does represent the local blood flow. A few other single compartment curves were obtained but were omitted because they were found in connection with signs of circulatory distress.

The blood flow values found are very high, expecially as they can be presumed to represent capillary flow and do not include flow through arterio-venous shunts. Furthermore they show a tendency to increase as the pregnancy progresses. Unfortunately this trend could not be examined further as the development of the placentae invalidates the method. The high values found do, however, correlate well with the active secretory state of the glandular cells and the high rate of cell multiplication in the decidua.

These results show that there is a high endometrial blood flow in early pregnancy at a time when progesterone secretion is increasing. 


\section{References}

ERNER-JENSEN, N. (1976) Endometrial blood-flow in the rat. Hormone Research (in press).

GREISS, R.C. \& ANDERSON, S.G. (1973) Effects of ovarian hormones on the vascular uterine bed. Am.J. Obstet. Gynec. 117, 386-388.

SeTchel, B.P., WatTes, G.M.H. \& ThORBURN, G.D.
(1966) Blood flow in the testis of the conscious ram measured with krypton. Circul. Res. 18, 755-765. Spaziani, E. \& Sumdick, R.P. (1967) Hexose transport and blood flow rate in the uterus: effects of estradiol, puromycin and actinomycin. Endocrinology 81, 205212.

Received 17 September 1976 